\title{
RDF Structure Investigation of Densified Silica Glasses
}

\author{
Kazuo YAMANA, Masayasu TOKONAMI* and Asao NAKANO** \\ Industrial Research Institute of Ishikawa Prefecture, Ro-1, Tomizu-machi, Kanazawa-shi 920-02 \\ * Faculty of Science, University of Tokyo, 7-3-1, Hongo, Bunkyo-ku, Tokyo 113 \\ ** Production Engineering Research Laboratory, Hitachi Ltd., 292, Yoshida-cho, Totsuka-ku, Yokohama-shi

\section{動径分布関数による高密度シリカガラスの構造研究}

\author{
山名一男・床次正安*, 中野朝雄**
}

石川県工業試験場，920-02 金沢市戸水町口-1

* 東京大学理学部, 113 東京都文京区本郷 7-3-1

** 日立製作所生産技術研究所，244 横浜市戸塚区吉田町 292

\begin{abstract}
A large magnitude of pressure was hydrostatically applied on silica glass. After removing the compression pressure, the silica glass shows an increase in refractive index and also in density, which is corresponding to the pressure. X-ray photographs of the densified specimens indicate that the profile of scattering intensities of haloes are different from those of the normal silica glass. The position of the strongest intensity shifts toward the higher angle with increasing the compression pressure. The manner of the structure changes of silica glass with increasing the compression pressure is discussed based on the ring structure-model of the $\mathrm{SiO}_{4}$ tetrahedra and the radial distribution functions calculated from the profiles of the scattered intensities.

[Received June 29, 1989 ; Accepted January 25, 1990]
\end{abstract}

Key-words : Silica glass, Densification, Radial distribution function

\section{Introduction}

Cohen and Roy ${ }^{1)}$ experimentally investigated the increase in refractive index for various kinds of glasses after removing the pressure. They observed that the magnitude of the increase in the refractive index is strongly related to the compression pressure. They proposed the hypothesis that the glasses underwent the second-order structural changes which obey a monotonous function of the pressure that the specimens are located under.

Bridgman and Simon ${ }^{2)}$ first described that glasses are permanently compacted by the pressure. They pointed out that the compression of glasses would be pictured as some kinds of folding up of the vitreous networks.

In this paper, the structures of densified silica glasses are investigated by radial distribution functions calculated from X-ray scattering intensities. The increase in the density and refractive index is disscussed on the view-point of the arrangement of the $\mathrm{SiO}_{4}$ tetrahedra in a silica glass.

\section{Experiment and result \\ 2.1 High pressure experiment}

Pure silica glass obtained from Toshiba Ceramics Company was used as a starting material to make specimens in this study. The glass was flame fused and specimens were nearly $1-3 \mathrm{~mm}$ in diameter and were spherically scrapped to be 1-2 mm by Bond's method. ${ }^{3)}$

DIA-15 type high pressure apparatus of the Osaka University was employed for the compression of specimens at $5 \mathrm{GPa}$ and $\mathrm{MA}-8$ type apparatus of the Nagoya University at $10 \mathrm{GPa}$. The glass specimens were embedded in pyrophyllite containers, in order to lie under hydrostatic pressure during the compression experiments. The graphite heating elements were used for ascending the specimen temperature. The specimens were subjected to a desired pressure at room temperature, and then heated to $500^{\circ} \mathrm{C}$ where the pressure was maintained for ten minutes. The specimen was cooled to room temperature by switching off the heater current, and finally the compression pressure was released.

The densities of specimens were determined by the sink and float test in a mixture of two kinds of 
liquids (benzene, $d=0.879$; methylene iodine, $d=3.32$ ). The densities of the test liquids were pycnometrically measured, which correspond to those of the specimens. The results are as follows:

$\begin{array}{cc}\text { load pressure }(\mathrm{GPa}) & \text { density }\left(\mathrm{Mg} / \mathrm{m}^{3}\right) \\ 0 & 2.20 \\ 5 & 2.48 \\ 10 & 2.78\end{array}$

\section{2 X-ray diffraction measurement}

Densified silica glasses, nearly spherical shape with $1-2 \mathrm{~mm}$ in diameter, were prepared for the $\mathrm{X}$-ray analysis. The photographs are represented in Fig. 1. The diffraction patterns of the densified silica glasses exhibit an isotropy on X-ray photographs and are similar to that of the original silica glass. However the strongest position of the halo shifts toward the higher angle with the increase of the compression pressure the specimen underwent. In addition to the haloes, weak but sharp rings were observed in the X-ray photgraphs of the compressed specimens. The origin of the rings is concluded to be caused by the existence of crystalline phases which are on the surface of the specimens, being combined with pyrophyllite container.

The scattered intensities were measured on a Rigaku four-circle diffractometer using $\mathrm{MoK} \alpha$

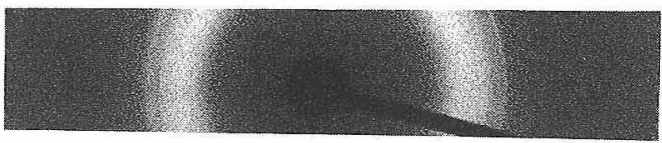

\section{$5 \mathrm{GPa}$}

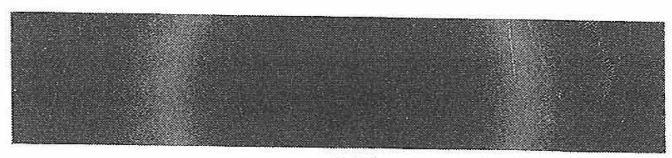

$10 \mathrm{GPa}$

Fig. 1. X-ray photographs of densified silica glasses.

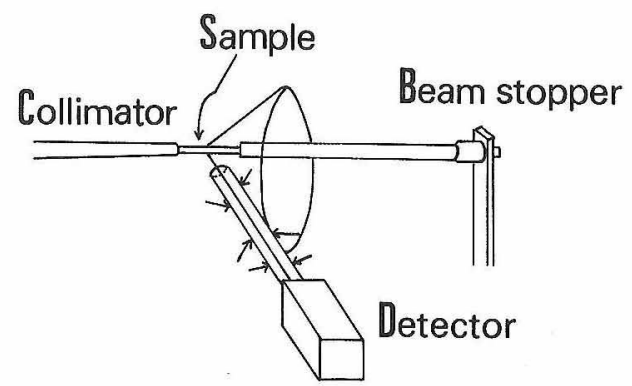

Fig. 2. Improved beam stopper equipped with Au tube and noise shield pipe equipped in front of scintillation counter. radiation monochromatized with pyrolytic graphite. The intensities of scattered X-rays were measured through the scintillation counter. The specimens were set up on a top of lithium aluminate whisker to reduce the scattered noise intensities. In order to reduce noise X-rays which are due to an air-scattering, the beam stopper was improved for this work and a noise shield pipe was equipped in front of a scintillation counter. The equipments are shown in detail in Fig. 2. The profile of the scattering intensities was sampled at an interval of 0.077 in $s=4 \pi \sin \theta / \lambda$, using $0.5^{\circ}$ receiving slit. 170 intensities were obtained by a step scanning method with 100 seconds counting at each step.

Four or six sets of the data were collected for each specimen and averaged in order to reduce the statistical error of counting and the short-time instabilities in the diffractometer system. The scattered intensity data were obtained from the observed intensities after the subtraction of the background intensities which were measured without the specimen on the four-circle diffractometer. The scattered intensity profiles were finally obtained after the absorption and polariza-

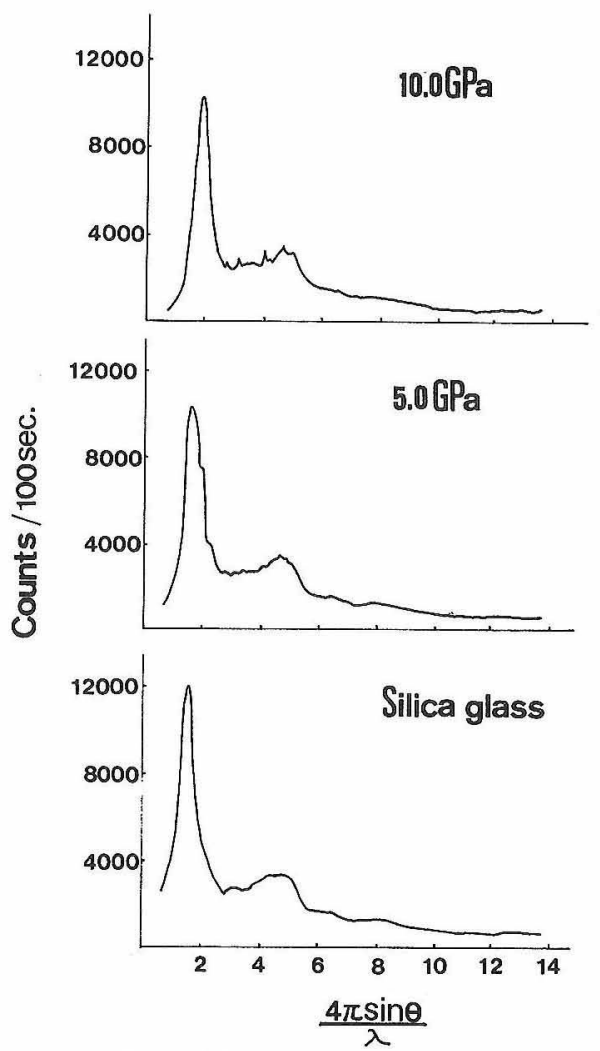

Fig. 3. Profiles of X-ray scattered intensities for the normal silica glass, the densified silica glass by $5 \mathrm{GPa}$, and the densified silica glass by $10 \mathrm{GPa}$. 
tion correction. The spherical absorption factors were taken from the International Tables for X-ray Crystallography Vol. II. ${ }^{4)}$ A polarization correction was made owing to use the graphite monochromator with MoKa radiation. The observed intensity profiles are shown in Fig. 3.

2.3 Calculation of radial distribution function

Zernike and Prins ${ }^{5}$ suggested that the radial distribution function (RDF) is determinable from the X-ray scattering intensity profiles. An alternative expression of the theory has been given by Warren and Gingrich. ${ }^{6)}$ The coherent scattering intensity in electron units scattered by a glass phase is given by "Debye's equation" :

$$
I_{\mathrm{eu}}^{\mathrm{coh}}(S)=\sum_{\mathrm{n}} \sum_{\mathrm{m}} f_{\mathrm{n}} f_{\mathrm{m}} \frac{\sin S r_{\mathrm{nm}}}{S r_{\mathrm{nm}}}
$$

where $f_{\mathrm{n}}, f_{\mathrm{m}}$ are the atomic scattering factors for $\mathrm{n}$ th and $\mathrm{m}$ th atoms, respectively, $r_{\mathrm{nm}}$ is the magnitude of the vector separating these atoms respectively, and $S=4 \pi \sin \theta / \lambda$. Introducing an atomic distribution function $\rho(r)$, the following equations are finally lead:

$$
\begin{gathered}
4 \pi r^{2} \sum_{\mathrm{m}} K_{\mathrm{m}} \sum_{\mathrm{n}} K_{\mathrm{n}} \rho_{\mathrm{n}}(r)=4 \pi r^{2}\left(\sum_{\mathrm{m}} K_{\mathrm{m}}\right)^{2} \rho_{0} \\
+\frac{2 r}{\pi} \sum\left(K_{\mathrm{m}}^{2}\right) \int_{0} S i(S) \sin r S \mathrm{~d} S \quad(2)
\end{gathered}
$$

where $i(S)=\frac{I_{\text {eu }}^{\mathrm{con}}(S)}{N \sum\left\{f_{\mathrm{m}}^{2}(S)\right\}}-1$

and $K_{\mathrm{m}}$ is the average effective electron number for atoms of type $m$.

To obtain RDF, normalization of observed scattering intensities was carried out adopting the high-angle region method. ${ }^{7}$ The atomic scattering factors were taken from Cromer and Waber. ${ }^{81}$ Compton scattering correction ${ }^{9)}$ was employed in this paper. In oder to reduce the termination effect of the integration, a convergence factor was introduced and RDF was calculated dy Warren's method. ${ }^{10)}$ The scattering intensities, ranging in $S<0.77$, which could not be observed because of the limitation of the diffractometer, were assumed not to occur any distinct peaks during $0<r<$ $1.0 \AA$ in RDF.

The calculated RDFs are presented in Fig. 4, corresponding to the specimens which underwent the pressure 0,5 and $10 \mathrm{GPa}$, respectively. The summation over uc means the summation over all the atoms in the unit of composition. Figure 5 shows a RDF in the relation of $r$ vs. $\sum K_{\mathrm{m}} 4 \pi r_{\mathrm{m}}^{2}$ $\left(\rho_{\mathrm{m}}-\rho_{0}\right)$, where $\rho_{0}$ is a constant average density of atoms of the specimen. The RDF expresses the radial distribution of atoms more plainly than those of Fig. 4.

\section{Discussion}

In a silica glass, there are three kinds of

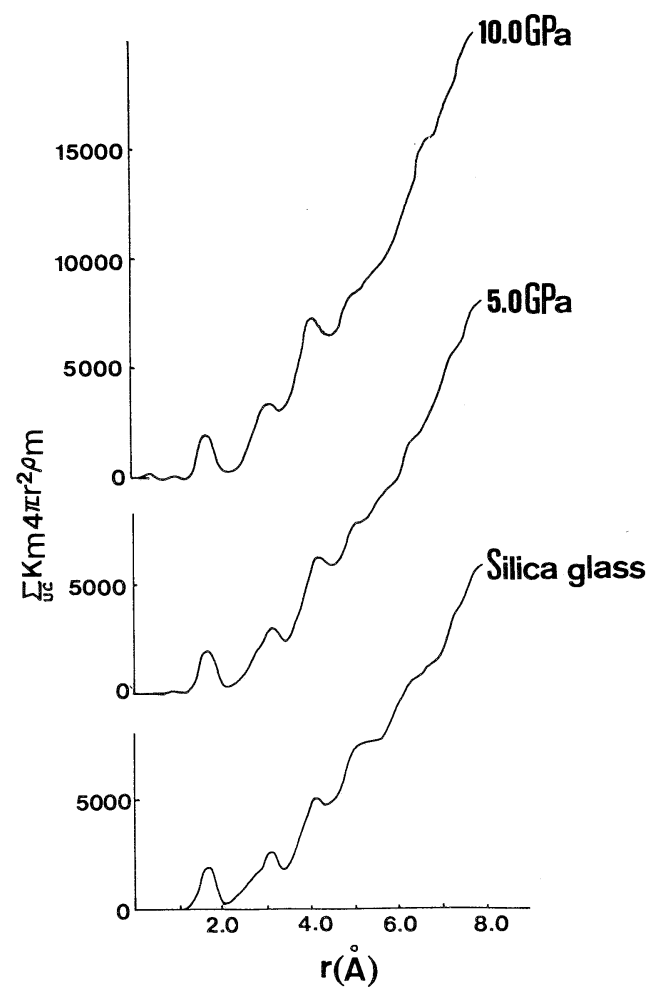

Fig. 4. Radial distribution functions in the relation of $\sum K_{\mathrm{m}} 4 \pi r^{2} \rho_{\mathrm{m}}$ vs. $r(\AA)$ for the non-densified silica glass, the densified silica glass by $5 \mathrm{GPa}$ and the densified silica glass by $10 \mathrm{GPa}$.

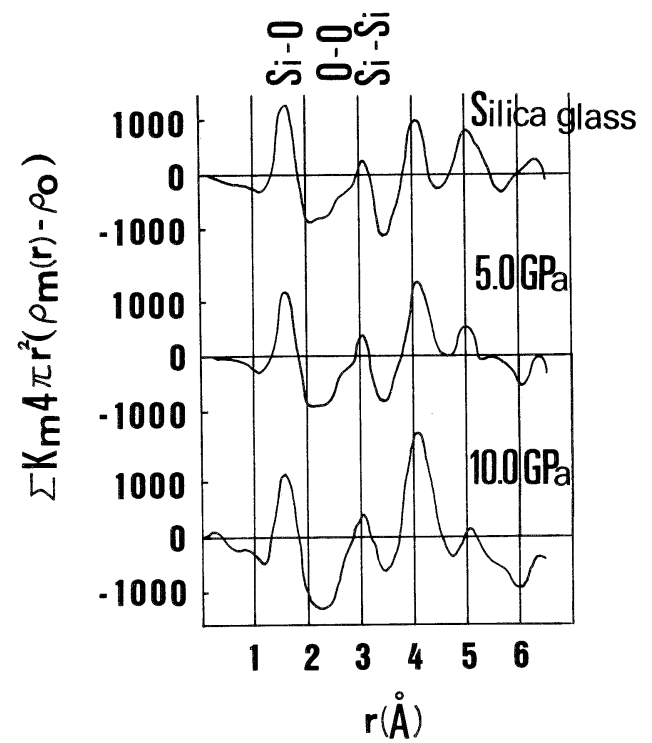

Fig. 5. Radial distribution functions in the relation of $\sum K_{\mathrm{m}} 4 \pi r^{2} \rho_{\mathrm{m}}$ vs. $r(\AA)$ for three kinds of specimens.

interatomic relations, $\mathrm{Si}-\mathrm{Si}, \mathrm{Si}-\mathrm{O}$ and $\mathrm{O}-\mathrm{O}$ and approximate values of each interatomic distance are known from those of the crystalline silica. The interatomic distances in the specimen are 
obtainable from the peak positions of the RDF patterns. If the peak, originating from atomic pair $\mathrm{p}$ and $\mathrm{q}$, is discrete between $r_{\mathrm{p}}$ and $r_{\mathrm{q}}$ in the RDF patterns. The coordination number is also obtainable from the integral area of the following relation ${ }^{111}$ :

$$
N_{\mathrm{pq}}=\frac{\int_{\mathrm{r} 1}^{\mathrm{r} 2} 4 \pi r^{2} \sum_{\mathrm{m}} K_{\mathrm{m}} \sum_{\mathrm{n}} K_{\mathrm{n}} \rho_{\mathrm{n}}(r) \mathrm{d} r}{K_{\mathrm{p}} \cdot K_{\mathrm{q}}+K_{\mathbf{q}} \cdot K_{\mathrm{p}}}(3)
$$

Since the atomic number of oxygen is small comparing to that of silicon, the peaks in RDF patterns express almost $\mathrm{Si}-\mathrm{O}$ and $\mathrm{Si}-\mathrm{Si}$ relations. According to the Eq. (2), the peaks of $\mathrm{Si}-\mathrm{Si}$ realtion are dominant in the longer $r$ region.

The shortest interatomic distance is about 1. $6 \AA$ and is almost same value in the densified and nondensified silica glasses. The distance corresponds to $\mathrm{Si}-\mathrm{O}$ distance found in crystalline silica minerals. $K_{\mathrm{p}} \cdot K_{\mathrm{q}}+K_{\mathrm{q}} \cdot K_{\mathrm{p}}$ in the Eq. (3) is 224 when $\mathrm{p}$ and $\mathrm{q}$ are $\mathrm{Si}$ and $\mathrm{O}$, respectively. The observed integrated area of $\mathrm{Si}-\mathrm{O}$ peak in the $\mathrm{RDF}$ is 890 electron $^{2}$ for the specimen undergone by 5 $\mathrm{GPa}$ pressure and 916 electron $^{2}$ for $10 \mathrm{GPa}$. The coordination numbers of the specimens are 4.0 and 4.1 for $5 \mathrm{GPa}$ and $10 \mathrm{GPa}$, respectively. The result indicates that silicon atoms in the densified silica glasses are tetrahedrally coordinated with four oxygen atoms, as in the normal silica glasses. The peak corresponding to $\mathrm{O}-\mathrm{O}$ in the RDF patterns is not distinct but recognizable at about 2.6-2.7 $\AA$. Though it is expected that silicon atoms in the densified silica glasses are coordinated with six oxygen atoms, the basic structure is unchangeable and silicon atoms exist in tetrahedra even if the glass has been compacted under the compression pressure of 5 or $10 \mathrm{GPa}$. If higher pressure is given to increase the coordination of silicon, in fact the silica glass seems to change into the six-coordinated crystal such as stishovite rather than six-coordinated glass because the silica glass cannot exist as an amorphous material following to a drastic change. Therefore the densification of the silica glass must be explained by the connection of $\mathrm{SiO}_{4}$ tetrahedra.

The connection of $\mathrm{SiO}_{4}$ tetrahedra is considered to be chains and rings which were found in various crystalline silica minerals. ${ }^{12)}$ The cause of the polymorphism is explained by the fact that the bond of Si-O includes both of ionic and covalent bonds. Following to the change of the temperature and the pressure producing a crystalline substance, the relative ratio of ionic and covalent bonds changes in $\mathrm{Si}-\mathrm{O}$ bond, and affects the bond angle of the $\mathrm{O}-\mathrm{Si}-\mathrm{O}$. Many crystalline forms are consequently produced in silica.
At atmospheric pressure, a silica has three crystalline forms such as quartz, tridymite and cristobalite. Furthermore, each of the three forms shows a low and high temperature modification. Crystal structures of the three main forms are built of $\mathrm{SiO}_{4}$ tetrahedra linked together. The arrangement of the linked tetrahedra is quite different in the three crystals. However, the three forms constitute the 6 -membered ring of tetrahedra. In the high-and low-temperature forms of one of the three varieties, there is slight rotations of the tetrahedra relative to one another without any alternation of the arrangement linking tetrahedra.

In high-pressure forms of silica, there exist three crystalline forms such as coesite, keatite and stishovite. The last form has the 6coordinated rutile structure. Coesite and keatite are based on 4-connected frameworks, and the smallest rings are respectively 4-(and 8-) membered ring (coesite) and 5-(7- and 8-) membered rings (keatite). Similarly, for noncrystalline silica, Revesz ${ }^{13)}$ pointed out that there exist various structural conformations based mostly on 4-8 membered rings, owing to the flexibility of the $\mathrm{Si}-\mathrm{O}-\mathrm{Si}$ bond.

The bond distances of ideal 4-,5- and 6membered rings of tetrahedra were calculated about the $\mathrm{Si}-\mathrm{Si}$ between tetrahedra in respective rings. In this calculation, the $\mathrm{Si}-\mathrm{O}$ and $\mathrm{O}-\mathrm{O}$ in tetrahedra was respectively given as $1.64 \AA$ and $2.65 \AA$. The calculated values are shown in Fig. 6.

The Si-Si interatomic distances are about $3.1 \AA$ obtained from RDFs of not only non-
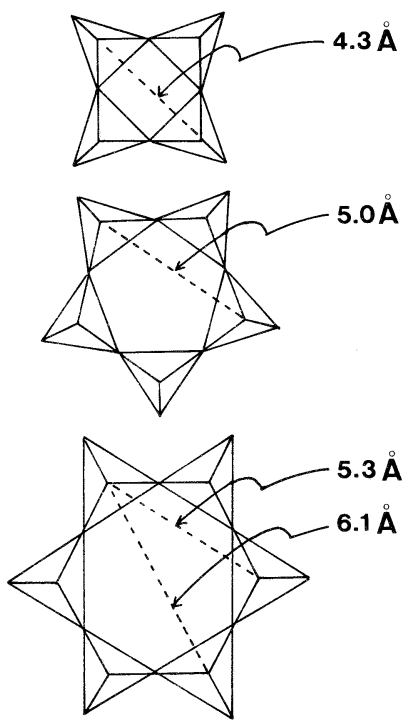

Fig. 6. Ideal 4-, 5- and 6-membered rings of tetrahedra, where the bond distances show the ideal $\mathrm{Si}-\mathrm{Si}$ between tetrahedra in respective rings. 
densified silica glass but also the densified ones. This distance means that $\mathrm{Si}-\mathrm{O}-\mathrm{Si}$ is bent with the angle of about $140^{\circ}$ and the average angle does not change even if the silica glass underwent the compacting pressure.

The interatomic distance of $4.1-4.2 \AA$ is observed in the RDFs of the non-densified and the densified silica glass. The integrated area of 4.1-4. $2 \AA$ peak in the RDFs grows larger with increasing the compacting pressure the specimen underwent. It is known from Cartz's model ${ }^{14)}$ that the distance corresponds to $\mathrm{Si}-\mathrm{O}$ between $\mathrm{SiO}_{4}$ tetrahedra consisting of 5-, 6- and 7-membered rings. However, it is similarly explained that the distance corresponds almost to that of 4 membered ring in Fig. 6 . In addition, the integrated area around 4.1-4.2 $\AA$ peak of densified silica glasses is so large that $\mathrm{Si}-\mathrm{Si}$ interaction must be contributed as well as $\mathrm{Si}-\mathrm{O}$ interaction. This indicates either that the 4-membered rings exist and/or that the more than 5-membered rings suffer remarkable distortion. The latter case. however, seems to be not likely for the densified silica glasses, because such the large distortion would not retain after the compression stress were released. Therefore, it is suitable to give the explanation that $\mathrm{Si}-\mathrm{Si}$ interatomic distance of 4 -membered rings grows dominant with the increase of the compacting pressure.

The $5.0 \AA$ peaks in the RDFs of the specimens are possibly referred to $\mathrm{Si}-\mathrm{Si}$ interatomic relations of 5-membered rings of the $\mathrm{SiO}_{2}$ tetrahedra in Fig. 6. The 5.1 $\AA$ peak is observed in the RDF of the non-densified silica glass and the peak is slightly shortened with the increase of the compacting pressure. The integrated area of the peak grows small with the increase of the compacting pressure. These indicate that the 5 -membered ring structure is dominant only in the nondensified silica glass and that the densification of the silica glass by the compacting pressure decreases the ring structure.

The RDFs from the scattering intensities of the silica glasses reveal that the large ring structure of $\mathrm{SiO}_{4}$ tetrahedra diminishes with increasing the compression pressure. The result is indicating that the compression pressure destroys the large circuit such as 5-or 6-membered $\mathrm{SiO}_{4}$ tetrahedra and construct the small circuit such as 4membered rings. The mechanism of the densification of the silica glass is explained by the shortening of the ring structure by the compression pressure.

Acknowledgments The authors thank Prof. M. Koizumi in Ryukoku University and Prof. N. Morimoto in Osaha Sangyo University who provided the guidance and the advice through out this work. Thanks are due to Prof. M. Shimada in Tohoku University, Prof. M. Kumazawa in Tokyo University and Prof. H. Sawamoto in Nagoya University who kindly carried out high pressure experiments.

\section{References}

1) H. M. Cohen and R. Roy, Phys, Chem. Glasses, 6, 149-61 (1965).

2) P.W. Bridgman and I. Simon, J. Appl. Phys., 24, 405-13 (1953)

3) W. L. Bond, Rev. Sci. Instr., 22, 344-45 (1951).

4) International Tables for X-ray Crystallography Vol. II, The Kynoch Press, Birmingham, England (1959).

5) F. Zernike and J. A. Prins, Z. Phys., 41, 184-94 (1927).

6) B.E. Warren and N.S. Gingrich, Phys. Rev., 46, 368-72 (1934).

7) Y. Waseda and M. Ohtani, Kinzoku Gakkai, 27, 117-26 (1971).

8) D. T. Cromer and J. T. Waber, Acta Cryst., A 24, 321-24 (1968).

9) D. T. Cromer, J. Chem. Phys, 50, 4857-59 (1969).

10) B.E. Warren, "X-ray Diffraction", Addision Wesley Publishing Co. (1969).

11) K. Furukawa, Rep. Prog. Phys., 25, 395-440 (1962).

12) R. Kiriyama, "Structural Inorganic Chemistry III (in Japanese)", Kyoritsu Zensho (1978).

13) A. G. Revesz, J. Non-Cryst. Solids, 7, 77-85 (1972).

14) L. Cartz, Z. Kristallogr., 120, 241-46 (1964). 